\title{
Diversity and Inclusivity in the Health Science Professions in the USA: A Case Study From Nursing History
}

Sandra B. Lewenson

Pace University, College of Health Professions, Lienhard School of Nursing, slewenson@pace.edu

Jane Bear-Lehman

Binghamton University, Decker College, Binghamton, NY, jane.bearlehman@binghamton.edu

Follow this and additional works at: https://qane-afi.casn.ca/journal

Part of the Medicine and Health Sciences Commons

\section{Recommended Citation}

Lewenson, Sandra B. and Bear-Lehman, Jane (2020) "Diversity and Inclusivity in the Health Science Professions in the USA: A Case Study From Nursing History," Quality Advancement in Nursing Education - Avancées en formation infirmière: Vol. 6: Iss. 2, Article 3.

DOI: https://doi.org/10.17483/2368-6669.1213

This Article is brought to you for free and open access by Quality Advancement in Nursing Education - Avancées en formation infirmière. It has been accepted for inclusion in Quality Advancement in Nursing Education - Avancées en formation infirmière by an authorized editor of Quality Advancement in Nursing Education - Avancées en formation infirmière. 


\section{Introduction}

During the fall of 2018, the Chronicle of Higher Education published a series of articles about diversity and inclusivity in what are known as the STEM courses, comprising science, technology, engineering, and mathematics (Blain, 2018; Case, 2018; Supiano, 2018). It was noted that many schools in higher education have a difficult time attracting, admitting, and graduating a diverse class of students in general and especially in the STEM courses. Since the STEM courses serve as a gateway into many of the health science professions that are found in universities and colleges across the United States, it has an impact on the diversity and inclusivity in these professions. There is a notable lack of diversity in race or gender among the health science faculty teaching in those programs, yielding fewer role models for those diverse students that should be admitted. The health science faculty and their students include undergraduate and graduate professional health care programs housed in universities. For the most part, professional programs such as occupational therapy, physical therapy, and speech language pathology require a master's or clinical doctoral level for entry into practice and require the support of the university in social and biological sciences. In nutrition and dietetics, as well as nursing, entry into practice can be found at the associate, baccalaureate, master's, and even doctoral level and requires academic coursework in the STEM courses, as well as a strong liberal arts background. Although the medical profession struggles with the same issues as the other health sciences, albeit in a different manner, this paper focuses on the typically female-dominated professions that follow a more similar educational pattern. The professional programs bring students to the academy, and in turn the academy offers much to these professions.

Diversity and inclusivity is the mantra and the challenge of higher education, especially in the health sciences. Efforts to increase diversity over time, even in the face of professional accreditation criteria and changing social values, however, has made few inroads in these areas (Blain, 2018; Green et al., 2007; Ramaswamy \& Kelly, 2015; Sullivan Report, 2004). Health science programs situated in universities experience a lack of diversity in their race and gender composition, creating a vacuum of a diverse work force. It is known that faculty and students both respond better to role models who reflect similar backgrounds (Rainey et al., 2018). Among health science faculty, unlike other university faculty, women dominate, thus leaving men who enter the professions with fewer examples to follow. Racial diversity mirrors a similar pattern, whereby the White faculty typically dominate the positions over Black and other underrepresented groups.

This paper explores the literature surrounding diversity and inclusivity in the health professions and uses a historical case study from nursing, one of the largest and oldest of the health science professions, to see the impact history has had on inclusivity and diversity. The case study reflects nursing's struggle to develop educational and professional standards in the United States between the end of the 19th and the early part of the 20th century, a period when prejudice reigned either by law (in southern states) or by custom (in northern states). The National Association of Colored Graduate Nurses (NACGN), one of the four professional nursing associations to organize during this period (1908-1952) in the United States, began to address the blatant racial bias in nursing and health care, along with the development of professional standards. This organization, and the issues it had to address, provides the historical context of inclusivity and diversity in nursing education and practice settings. Several of the health science professions shared a similar background to that of nursing during the early 20th century (Metaxas, 2000). As a result, the developing nursing profession can serve as an exemplar as to how it addressed racist laws in the southern part of the United States and attitudes across the country that permeated nursing education 
in hospital- and university-based programs. The overt racism of the Jim Crow era, where racial separation in the southern states was legalized from the late 19th century through the mid-20th century; the institutional racism that continues in our universities and hospital systems; and the implicit bias that affects us all have contributed to the ongoing dilemma faced today (Barbee, 1993; Hine, 1989; Ramaswamy, \& Kelly, 2015; Thoms, 1929/1985; Threat, 2015).

\section{Current Literature Reflecting Diversity and Inclusivity in the Health Sciences}

Nursing and the four health professions (occupational therapy, physical therapy, speech language pathology and audiology, and nutrition) are typically the cohort of professional health science academic credentialled programs sometimes housed together in universities across the United States, and all identify faculty shortages (American Association of Colleges of Nursing, 2017; American Occupational Therapy Association, 2018; Bittner \& Bechtel, 2017; Commission on Accreditation Physical Therapy Education, 2017; Council on Academic Accreditation in Audiology and Speech-Language Pathology, 2018; McNeal, 2012). Even though they recognize the longstanding need to diversify, these health care professions are not significantly diversifying faculty to meet these needs, the guidelines for higher education, their own professional guidelines, or accreditation standards such as the American Academy of Nursing, the American Association of Colleges of Nursing (AACN), Accreditation Council for Occupational Therapy Education (ACOTE), Commission on Accreditation in Physical Therapy Education, the American SpeechHearing Association (ASHA), and the Accreditation Council for Education in Nutrition and Dietetics (ACEND). This affects their ability to provide culturally competent educational experiences that have the potential to produce a culturally competent diverse workforce (American Association of University Professors [AAUP], 2000; Sullivan Report, 2004).

\section{Effect in the Classroom}

The longstanding history of racial inequity in the United States leads to a continuation of the incidence of institutional racism (Nash, 2017). This form of racism, which still exists, plays out in all aspects of the classroom, including teaching/learning process and the outcomes, as well as in the health care arena. This has profound meaning for students who are interested in the sciences but fail to accomplish the grades needed to enter these fields. Supiano (2018) writes of the experience of Kelly A. Hogan and her work researching large courses, specifically, biology 101. Hogan used "inclusive teaching which [seeks] to level the playing field equalizing the opportunity for students in all backgrounds to participate and succeed" (Supiano, 2018, A.15). Hogan had an "aha" moment when she recognized that the differences in the scores of her students in the gateway undergraduate biological stem course was drawn by race. Only one in 14 White students failed the course compared to one in three Black students (Supiano, 2018, A.14). This reflection, both quantitatively and qualitatively, led her to recognize the invisible and insidious inequities in the classroom. This occurred in her school where diversity was purposefully sought in undergraduate admissions, and yet the outcome of the course revealed that these inequities continued to adversely affect their success in the STEM courses. This in turn prohibited the students from satisfying the needed requirements to enter any of the health science professions. Supiano (2018) described the possibilities of alternative strategies in teaching and learning that lead to culturally sensitive faculty development. For example, the uneven resources that faculty received when given an assignment to make a mobile out of materials provided on a table mirrored the uneven resources that students bring into the classroom. This led to open dialogue among the participants about approaching classroom teaching with better understanding of the various capacities the student/learner brings to the classroom. The article calls for an inclusive-teaching 
method that builds on the inclusion for student success. Supiano advises increase structure and active learning as part of an inclusive teaching method. While this may not retract the inequities, it can provide some strategies and alternative ways of confronting these issues and increase the opportunity for success in STEM courses among students regardless of race or ethnicity.

\section{Effect of Power and Belonging}

Other issues in the literature that relate to diversity and inclusivity pertain to power and belonging. In a recent Chronicle of Higher Education article, Ambar (2018) explains that power issues and the status quo need to change for there to be a significant shift. Also, a lack of recognition of the inequity within higher education - specifically in the sciences - in the academy further compounds the lack of sufficient number of diverse faculty and students. A sense of belonging is another important concept that influences the success of students in terms of academic achievement and retention (Rainey et al., 2018). For example, students of colour and White women felt a greater sense of belonging when they were part of the larger conversations both in and outside class. Without feelings of connectedness to their faculty or others in their course or fields, these groups felt an increased sense of loss of belonging and marginalization that ultimately led to a lack of academic achievement and threatened their success. Rainey et al. (2018) noted that students of color and White women in the STEM professions are underrepresented; thus, these students lack a sufficient number of role models or faculty that can offer them a sense of belonging. When students experience marginalization in these STEM classes, they can no longer progress into the health care professions, and for this paper, this would mean the inability to progress into nursing, occupational therapy, physical therapy, speech language pathology and audiology, or nutrition. Additionally, aside from race and gender inequity, students' professional goals might also impact their sense of a belonging. Anecdotally, students interested in a specific health care profession have identified feeling a discriminatory attitude about their place in the course populated by students who are primarily studying science or are pre-med. This raises the ongoing debate in the literature (which is beyond the scope of this paper) as to whether the health care professions are considered STEM. Regardless, though, most agree that health care professions are considered secondary STEM and that students must be successful in STEM coursework to succeed (Hedgecock, 2016). It is essential then to develop an understanding of the past inequities, to consider the various ways to reflect on faculty student diversity, and to explore various strategies to change this pattern. This paper begins the process of developing an appreciation for building and sustaining an increasingly diverse health science faculty workforce. History offers another relevant strategy for understanding the lack of diversity and rationale for why this is so.

\section{Brief History of the Health Sciences in Higher Education}

Professional nursing started in 1873 during the infamous Jim Crow period that had begun in the post-reconstruction era following the Civil War. During these times, laws not only called for segregated work, living, and play spaces, but also prohibited opportunities for racial diversity (Hine, 1989; Staupers, 1961). Early in the 20th century, health professions grew to include other specialties. The time period, the gender, and the racial context of the period are shared commonalities in these professions. For example, 1917 marks the beginning of occupational therapy and the professional association, the American Occupational Therapy Association, was created in 1921; physical therapy emerged somewhere around 1914, when Reed College granted degrees in reconstruction aides (an early term used to describe physical therapy), and the American Physical Therapy Association was begun in 1924; the year 1925 is given for the beginning of the 
speech, language, and hearing profession; and nutrition's association, ACEND, began a bit earlier in 1917 (Anderson \& Reed, 2017).

These other health care professions experienced the same racial bias and gender selectivity in schools, hospitals, and community as nursing did. They attracted White women for the most part and Black women when educational experiences were open to them. While health care professions often began in universities and colleges, nursing's educational experiences remained steady in hospital-based programs until the 1950s when associate degree programs formed and the profession, through the American Nurses Association, sought baccalaureate entry into practice degree programs in 1965. Earlier baccalaureate programs existed in nursing, such as the opening of the program at the University of Minnesota in 1909 and, even earlier, the advanced graduate programs (not typical degree granting) in home economics, teaching, administration, and public health nursing at Teachers College at Columbia University beginning in 1899. But these programs did not gain the wide acceptance of the two-year associate degree programs in the 1950s (McAllister, 2017). With the creation of the associate degree model of educating nurses, older women, women of colour, and men now found greater acceptance into these programs, thus increasing the opportunities for diversity (McAllister, 2017). In the United States, the dilemma of multiple educational entrance levels into nursing practice has continued throughout the 20th and into the 21 st century.

\section{Case Study from Nursing History}

The late 19th and early 20th century marks the beginning of what is known as the modern nursing movement (Lewenson, 1993). This was a time of professionalization of nursing through the founding of Nightingale-influenced nurse training programs, as well as the development of four professional nursing associations that would seek higher standards in nursing practice, education, and public health. One of those organizations, NACGN, which began in 1908, addressed the efforts to raise professional standards, along with backing a concerted effort for equality (Carnegie, 2000; Hine, 1989; Lewenson, 1993). The NACGN sought what we might now call inclusivity and diversity in nursing. This organization wanted recognition and acceptance in the nursing profession, as well as health care equity for the Black community-at-large. The other three professional nursing organizations - the Superintendents' Society (first formed in 1893 and now called the National League for Nursing); the American Nurses Association (ANA), which began in 1896; and the National Organization of Public Health Nursing, started in 1912 - initially did not exclude Black people from membership or from schools of nursing or practice. However, these organizations, for the most part, mirrored the commonly held biased customs in the northern states and the segregationist laws in the south (Lewenson, 2019). For example, ANA, when it first began in 1896, permitted Black members in the organization. But by (about) 1912, membership into the organization was obtained through state nursing associations rather than the national association, and as a result in several southern states, in particular, Black nurses were barred from individual membership.

Education for Black women did not fare much better, and many schools of nursing either refused Black women altogether, or set up quotas (D'Antonio, 2010). Even in schools that accepted Black students into nursing, they often did so with reservation, especially when it came to housing and clinical placement of these students (Hine, 1982; Johns Report, 1925). Nursing schools for Black women opened during the late 19th and early 20th century to provide the much-needed opportunities for these women (Hines, 1986). These programs supported the opening of Black hospitals that, out of necessity, formed to address the health of the Black population. The racial 
divide impacted the development of these programs, especially in the delivery of health care. Historian Darlene Clark Hine (1989) writes,

the discrepancies in the status and treatment of the two races were most apparent in the area of health-care delivery and in the virtual absence of educational and career opportunities for black women and men in the nursing and medical profession. Left with little recourse, the first generation of post-slavery black physicians, educators, and community leaders developed within their enclosed world a number of health care related institutions. (p. 3)

Blocking Black women from nurse training schools was compounded by the lack of postgraduate opportunities that nurses needed to serve in specialty-type settings, such as rural public health and in the military. For example, in 1912, the lack of sufficient educational prospects available to Black nurses hampered their ability to join the American Red Cross (ARC) and enter what was known as the ARC Town and Country Nursing Service (a rural public health nursing service) or to overcome the barriers they faced when trying to enter the Army Nurse Corps via the $\mathrm{ARC}$, the organization that maintained the gatekeeping role for nurses to enter the armed services or the US Public Health Service during World War I (Threat, 2015). In the first example, the ARC Town and Country required a three-year-diploma trained graduate nurse to have an additional postgraduate course in rural public health. Yet the schools in both the north and the south denigrated Black nurses' professional ability, as well as the school from which they may have graduated (Johns Report, 1925; Lewenson, 2015). In the Jim Crow south, Black nurses were turned away from these schools and found refuge in historically Black colleges and hospital-based nursing programs that had formed in response. In the north, however, prevailing racial biases deepened the disparity between the admission and success of students within programs that admitted them.

One Black nurse known to overcome some of the racial barriers was Frances Elliot Davis. Davis is considered to be the first Black nurse to enter the ARC Town and Country in 1917 and later the United States Public Health Service during World War I. Being a diploma graduate of Freedmen's Hospital School for Nurses in Washington, DC, in 1913, she met the ARC qualifications and had received a scholarship from the ARC to attend one of the few schools that would admit a Black student into a postgraduate course in rural public health at Teachers College, Columbia University in New York (Lewenson, 2019). Davis's admission into the ARC Town and Country demonstrated a change in policy of the ARC to admit Black nurses, but it did not herald an acceptance of these nurses in the ARC Town and Country or the entrance into the Army or Public Health Service via the ARC. The need for nurses during World War I and the 1918 influenza epidemic prompted the admission of other Black nurses, but as these nurses sought to serve during war time, they found themselves placed on a separate list of nurses admitted into the ARC with a designation of " $\mathrm{A}$ " on their Red Cross badges. This practice of separating Black nurses from White nurses on a list maintained the segregation of these nurses in housing and clinical placement (Lewenson, 2019; Threat, 2015). To the dismay of the NACGN, Black nurses never served in active duty during World War I because of the racially biased practices found in the military, the ARC, educational institutions, and hospitals (Carnegie, 2000). The separate list of Black nurses was maintained by the ARC from 1918 until 1949 (Lewenson, 2019).

A few years after World War I, the president of the NACGN, Adah Thoms (1921), addressed the NACGN in 1921 at the 14th annual meeting, where she called "for helping a number of nurses who desire higher education" (p. 3). Higher education was key to addressing the needs of both the profession and the larger Black population. To counteract the lack of access to rural 
public health nursing care, especially in the south, the Circle of Negro Relief, an organization that formed in 1917 to support the needs of the Black soldiers returning home from World War I and later reorganized to address the needs of Black populations during peace time, started the Blue Circle Public Health Nurses in 1918 (Circle for Negro Relief, 1923; Hine, 1989; Lewenson, 2019). The Blue Circle nurses were initially sent to three communities in the south as an experiment in public health nursing (Circle for Negro Relief, 1923). To match the qualifications of these nurses with those in the ARC public health rural nursing service, the Circle of Negro Relief raised scholarship funds to send a few interested Black nurses to receive the additional training as rural public health nurses. While few schools accepted these students, Teachers College at Columbia University accepted them into its program, as they had done earlier with Frances Elliot Davis (Lewenson, 2019).

\section{Historically Black Schools of Nursing and Universities}

With the legally sanctioned "separate but equal" doctrine that supported separate schools and hospitals for Blacks and Whites during the late 19th century, and the ever-increasing higher morbidity and mortality rates of Black Americans, philanthropic interest in addressing this issue emerged (Carnegie, 2000). The philanthropy of the John D. Rockefeller, Andrew Carnegie, and Julius Rosenwald foundations supported the emergence of these Black schools and hospitals. The Rockefellers provided the funding in 1881 to establish the Atlanta Baptist Female Seminary, which became one of the early historically Black institutions, Spellman College. Spellman opened a department of nursing in 1886 (Hine, 1989). By the early 20th century, other Black schools of nursing had appeared throughout the country, notably Provident Hospital School of Nursing (1891) in Chicago; Dixie Hospital Training School (1891) in Hampton, Virginia; the Tuskegee Institute Nursing Training Course (1892), which became the John A. Andrew Hospital and School of Nursing in Tuskegee, Alabama; and Freedmen's Hospital School of Nursing (which later became part of Howard University) in Washington, DC. Historically, Black universities organized with the same purpose: providing higher education for Black men and women. In these schools of higher education, you see the development of some of the nursing programs on the baccalaureate level, as well as some of the other health science fields.

The legacy of the separate but equal in schools of nursing and health care continued into the 1960s with changing social climate and federal laws. By this time, the NACGN had voted itself out of existence and had joined the ANA in 1951, realizing its goal to be integrated into the larger nursing body. Yet the firmly engrained ideas of racial divide continued well past the 1950s and continue to haunt higher education, especially in the health care professions. While race continued to be a factor in who became a nurse, gender also served to divide those who entered nursing and perhaps subsequently the other health professions (Threat, 2015). For most health care professions, women (Black and White) seem to be the dominant gender (except for medicine and dentistry, which until more recently were dominated by men). For example, $89 \%$ of occupational therapists today are White and $90 \%$ are women, and $78.9 \%$ of physical therapists are White and $65 \%$ are women.

\section{Discussion and Conclusion}

We began this paper by presenting the lack of sufficient diverse faculty either in race or by gender within the health care professions. We described the need for a diverse faculty and student body in the health care professions in higher education and some of the strategies that would support a more diverse student body, such as inclusive teaching strategies and concern for power 
and belonging. The historical case study showed that nursing, one of the largest and oldest of the health care professions, examined the racial boundaries set by law and custom in both the north and the south. Black nurses responded to the racially unjust society in which they lived and sought to improve health care and educational opportunities for the Black population. As noted earlier, the NACGN was created in 1908 by Black women who believed that nursing standards and education were essential for the health care of all. In practice, organizations such as the Blue Circle Public Health Nurses, under the auspices of the Circle of Negro Relief, attempted to address the lack of diversity in public health. The Circle did so by supporting the education of Black public health nurses to provide care to the Black population living in the south. The Civil Rights Movement of the 1960s expanded the admission opportunities in universities and colleges throughout the United States to include men and women of all backgrounds (AAUP, 2000; Sullivan Report, 2004). The newly organized health sciences, dating back to the early 20th century, continued to grow and expand. For many of these health science professions (e.g., occupational therapy and physical therapy), entry into practice began at the university and college level-some as certificate programs, which then advanced to bachelor's degrees, and then ultimately requiring a graduate degree to earn a licence to practise. This stands in stark contrast to nursing's multiple levels of educational entry into practice in the United States. Throughout its more than 100-year history, entry into the profession has continued to be met through multiple entry levels that allow for diversity of age, race, and gender. One can become a nurse through a diploma program (although mostly phased out in this country; some states still permit this level of practice), an associate degree, a baccalaureate degree, and even a generic master's degree. Nursing singlediscipline doctoral degrees, both practice doctorates (doctorate of nursing practice [DNP]) and research doctorates (PhD and EdD), show the advancement of nursing programs in higher education. While efforts to increase the number of doctoral-prepared nurses continues, about $1 \%$ of the over three million practising nurses have earned a doctorate ("The Future of Nursing," 2018; McNeal, 2012; "PhD in Nursing," n.d.). Of great concern is the decrease in the number of doctoral students in the pipeline, meaning that will be a further decline in the number of prepared nurse scientists and faculty (AACN, 2018). It is important to note here that while the numbers of doctoral students in the pipeline has decreased, data show an increase of students from underrepresented groups and men in these doctoral programs (AACN, 2018)

Yet even with the wide array of what can be interpreted as multiple points of entry in nursing, and even with data showing a trend (since the 1930s) of an increase of diversity, the licensed and credentialled health care professionals in this field are still dominated mostly by White women (D’Antonio \& Whelan, 2009; DeWitty \& Downing, 2018; Zajac, 2011). The effort to be more inclusive and diverse, however, continues to be an ever-present concern in nursing organizations, educational institutions, and practice settings (AACN, 2017, 2018). In physical therapy, a rise to $35 \%$ of men in the profession is noted, but in occupational therapy, speech language pathology and audiology, and nutrition, the increase in race and gender is minimal if at all (American Association of Colleges of Nursing, 2017; American Occupational Therapy Association, 2018; Commission on Accreditation Physical Therapy Education, 2017; Council on Academic Accreditation in Audiology and Speech-Language Pathology, 2018).

The early Black nurses who pioneered new organizations, educational experiences, and practice settings to improve the overwhelming poor morbidity and mortality statistics of Black communities did so in the context of racial disparity and inequality. Faced with laws prohibiting integration, they endured and developed other ways to circumvent the status quo of the period. Nursing's history serves as an example of how a profession reflected the context of the times in 
which it developed, leaving a legacy of racial prejudice that so many Black professionals experienced over time. The overt racism supported by the Jim Crow laws of the late 19th and early 20th centuries continues in forms of institutional racism and implicit bias (Barbee, 1993).

Yet efforts to diversify and be more inclusive continue, as evidenced by institutions of higher education engaging in strategies that support a more diverse community. Strategies such as admitting a more diverse student body, developing multiple educational entry levels into practice, and using teaching/learning strategies that support all students may contribute to changing the landscape. In addition, acknowledgement, study, and critique of the historical foundations in which our professional programs developed offers an opportunity for a meaningful dialogue among the various stakeholders. The numbers show who is missing from this larger conversation on campus, and unless we explore, question, and teach the history of the health science professions and learn from what we know, we are missing an opportunity to be more successful, to become more diverse and inclusive, and to meet the needs of the profession and the public. 


\section{References}

Academy of Nutrition and Dietetics. (2018). About accredited programs. https://www.eatrightpro.org/acend/accredited-programs/about-accredited-programs

Ambar, C. T. (2018, April 6). Our shameful support of the status quo. The Chronicle of Higher Education, 64(30), B10.

American Association of Colleges of Nursing. (2017). AACN position statement on diversity, inclusion, and equity in academic nursing. Journal of Professional Nursing, 33, 173-174. https://doi.org/10.1016/j.profnurs.2017.04.003

American Association of Colleges of Nursing. (2018). The PhD pipeline in nursing: Sustaining the science. https://www.aacnnursing.org/Portals/42/news/surveys-data/PhD-Pipeline.pdf

American Association of University Professors. (2000). Does diversity make a difference? Three research studies on diversity in college classrooms.

American Occupational Therapy Association. (2018). ACOTE accreditation. https://www.aota.org/Education-Careers/Accreditation.aspx

Anderson, L. T., \& Reed, K. L. (2017). The history of occupational therapy: The first century. Slack Incorporated.

Barbee, E. L. (1993). Racism in U. S. Nursing. Medical Anthropology Quarterly, 7(4), 346-362. http://www.jstor.org/stable/649214

Bittner, N. P., \& Bechtel, C. F. (2017). Identifying and describing nurse faculty workload issues: A looming faculty shortage. Nursing Education Perspectives; New York, 38(4), 171-176. https://doi.org/10.1097/01.NEP.0000000000000178

Blain, K. (2018). Power is still too white. The Chronicle of Higher Education, 64(30), B11.

Carnegie, M. E. (2000). The path we tread: Blacks in nursing, 1854-1994 (3rd ed.). Jones \& Bartlett.

Case, H. (2018). Seven theses on gender and power. The Chronicle of Higher Education, 64(30), B12.

Circle for Negro Relief. (1923). Our annual appeal letter for 1923. Jesse E. Moorland Papers, Box Organizations-C-N. Folder 622, The Circle of Negro War Relief. MoorlandSpingarn Research Center, Howard University, Washington, DC, United States.

Commission on Accreditation Physical Therapy Education. (2017). Program data, 2017-2018: Physical therapist education programs fact sheets. http://www.capteonline.org/uploadedFiles/CAPTEorg/About_CAPTE/Resources/Aggreg ate_Program_Data/AggregateProgramData_PTPrograms.pdf

Council on Academic Accreditation in Audiology and Speech-Language Pathology. (2018). https://caa.asha.org/

D'Antonio, P. (2010). American nursing: A history of knowledge, authority, and the meaning of work. The Johns Hopkins University Press.

D'Antonio, P., \& Whelan, J. (2009). The counting of nurses. Journal of Clinical Nursing, 18, 2717-2724. https://doi.org/10.1111/j.1365-2702.2009.02892.x 
DeWitty, V., \& Downing, C. (2018). New careers in nursing nationwide, 2007-2017. Interuniversity Consortium for Political and Social Research. http://doi.org/10.3886/ICPSR36758.v1

The future of nursing: Focus on education. (2015, May 5). Nurse Journal. https://nursejournal.org/articles/the-future-of-nursing-infographic/

Green, A. R., Carney, D. R., Pallin, D. J., Ngo, L. H., Raymond, K. L., Iezzoni, L. I., \& Banaji, M. R. (2007). Implicit bias among physicians and its prediction of thrombolysis decisions for Black and White patients. Journal of General Internal Medicine, 22(9), 1231-1238. https://doi.org/10.1007/s11606-007-0258-5

Hedgecock, S. (2016, March 29). Is nursing a STEM field? Even experts disagree. Forbes. https://www.forbes.com/sites/sarahhedgecock/2016/03/29/is-nursing-a-stem-field-doesit-matter/\#68c264135b47

Hine, D. C. (1982). The Ethel Johns Report: Black women in the nursing profession, 1925. Journal of Negro History, 67(3), 212-228. http://www.jstor.org/stable/2717387

Hine, D. C. (1989). Black women in White: Racial conflict and cooperation in the nursing profession, 1890-1950. Indiana University Press.

Johns, E. (1925). A study of the present status of the Negro woman in nursing. Rockefeller Foundation, Record Group 1.1, series 200, Box 122, Folder 1507, pp. 1-43 (p. 7). Exhibits A-P, Appendixes I and II. Rockefeller Archive Center, Pocantico, New York, United States.

Lewenson, S. B. (1993). Taking charge: Nursing suffrage, and feminism in America, 1873-1920. Garland Publishing.

Lewenson, S. B. (2015). Town and Country nursing: Community participation and nurse recruitment. In Nursing rural America: Perspectives from the early 20th century (pp. 119). Springer.

Lewenson, S. B. (2019). Hidden and forgotten: Being black in the American Red Cross Town and Country Nursing Service, 1912-1948. Nursing History Review, 27, 15-28.

McAllister, A. M. (2017). "On such teachers rests the future of nursing": Preparing faculty for associate degree programs in the mid-20th century. In S. B. Lewenson, A. M. McAllister, \& K. Smith (Eds.), Nursing history for contemporary role development (pp. 141-160). Springer.

McNeal, G. J. (2012). The nurse faculty shortage. ABNF Journal, 23(2), 23-23.

Metaxas, V. A. (2000). Eleanor Clarke Slagle and Susan E. Tracy: Personal and professional identity and the development of occupational therapy in progressive era America. Nursing History Review, 8, 39-70.

Nash, D. (2017). Health inequities in America. American Health \& Drug Benefits, 10(6), 279 280.

PhD in nursing. (n.d.). American Association of Colleges of Nursing. https://www.aacnnursing.org/News-Information/Research-Data-Center/PhD 
Rainey, K., Dancy, M., Mickelson, R., Stearns, E., \& Moller, S. (2018). Race and gender differences in how sense of belonging influences decisions to major in STEM. International Journal of STEM Education, 5, Article 10. https://doi.org/10.1186/s40594018-0115-6

Ramaswamy, M., \& Kelly, P. J. (2015). Institutional racism as a critical social determinant of health. Public Health Nursing, 32(4), 285-286. https://doi.org/10.1111/phn.12212

Staupers, M. K. (1961). No time for prejudice: A story of the integration of Negros in nursing in the United States. Macmillan.

Sullivan, L. W. (2004). Missing persons: Minorities in the health professions, A report of the Sullivan Commission on Diversity in the Health Workforce. https://drum.lib.umd.edu/handle/1903/22267

Supiano, B. (2018). Can a different approach to teaching fix inequality? The Chronicle of Higher Education, 64(33), A.14-A.18.

Thoms, A. (1921). Annual address of the president, Mrs. Thoms. Washington DC, 1921. Mabel Staupers Papers, Box 96-2, Folder 35. Howard University, Mooreland-Spingarn, Arthur B. Spingarn Papers Collection 94-1-94-4, Adah Thoms. Washington, DC, United States.

Thoms, A. B. (1985). Pathfinders: A history of the progress of colored graduate nurses. Garland Publishing. (Original work published 1929)

Threat, C. J. (2015). Nursing civil rights: Gender and race in the Army Nurse Corps. University of Illinois Press.

Zajac, L. (2011, Summer). Double-loop approach: Recruitment and retention of minority nursing faculty. The Association of Black Nursing Faculty Journal, 22(3), 73-77. 